\title{
« Effects of gain-loss frames on social preferences »
}

\author{
$\underline{\text { Auteurs }}$ \\ Kene Boun My, Nicolas Lampach, Mathieu Lefebvre
}

Document de Travail n² $2016-21$

November 2017

Faculté des sciences économiques et de gestion

Pôle européen de gestion et d'économie (PEGE) 61 avenue de la Forêt Noire

F-67085 Strasbourg Cedex

Secrétariat du BETA Géraldine Del Fabbro Tél. : (33) 0368852069 Fax : (33) 0368852070 g.delfabbro @unistra.fr www.beta-umr7522.fr 


\title{
Effects of gain-loss frames on social preferences ${ }^{\S}$
}

\author{
Kene Boun My* Nicolas Lampach ${ }^{\dagger}$ and Mathieu Lefebvre ${ }^{\ddagger}$
}

\begin{abstract}
The paper provides new experimental evidence on the difference between inequality aversion in the gain and in the loss domain. Incorporating loss aversion in the model by Fehr and Schmidt (1999) and relying on a modified dictator game as proposed by Blanco et al. (2011), we demonstrate that the parameter of inequality aversion is lower when the game is framed with losses than with gains. Individuals would be less inequality averse for losses than for gains. The results also manifest that women are more inequality averse than men.
\end{abstract}

Keywords: social preferences, inequality aversion, modified dictator game, loss aversion, laboratory experiment

JEL Classification: C70, C91, D63

\footnotetext{
$\S$ The authors gratefully acknowledge financial support by the project "Creative, Sustainable Economies and Societies" (CSES) coordinated by Robin Cowan, funded through the University of Strasbourg IDEX Unistra. We thank Guiseppe Attanasi, Dominik Bauer, Tarek Jaber-Lopez, Russel Neudorf, Sandrine Spaeter, Gisèle Umbhauer, the Editor and two anonymous reviewers of the journal of Economic Science Association for their helpful and constructive comments. All remaining errors are our own.

* BETA, CNRS and University of Strasbourg, 61 avenue de la forêt noire, 67085 Strasbourg, France.

$\dagger$ Corresponding Author: KU Leuven, Centre for Legal Theory and Empirical Jurisprudence, 41 Tiensestraat, 3000 Leuven, Belgium; E-mail: nicolas.lampach@kuleuven.be; Tel: +32 (0)16377608.

$\ddagger$ BETA, University of Strasbourg, 61 avenue de la forêt noire, 67085 Strasbourg, France.
} 


\section{Introduction}

There is large evidence that people are not only self-interested but are also concerned about the welfare of others. In a variety of economic situations, it has been shown that individuals exhibit other-regarding preferences such that concerns for fairness and reciprocity strongly motivate their decision. Several theoretical approaches have been developed to rigorously explain the observed phenomena (Fehr and Schmidt, 1999; Bolton and Ockenfels, 2000; Charness and Rabin, 2002) and their predictions have been confirmed by laboratory experiments in various settings (See Fehr and Fischbacher, 2006 for a review of this evidence).

Despite the large number of papers dedicated to this issue, there are few attempts to study other-regarding preferences in the loss domain. One question which has not been much explored is whether the decision frame affects a person's level of fairness. Indeed previous research in decision making has found that individuals treat losses and gains differently (e.g. Kahneman and Tversky, 1979; Kahneman, 1992; Köszegi and Rabin, 2006; Köbberling and Wakker, 2005). Particularly the possibility of loss aversion around a reference point has been shown to be an important phenomenon. The fact that people experience a disproportionately larger disutility from losses than from the same-sized gains has been helpful to explain a series of observed behaviors ${ }^{1}$.

Previous works from the literature on social psychology have shown that individuals are more own-outcome oriented in a situation where they face potential losses (Loewenstein et al., 1989; Poppe and Valkenberg, 1993; De Dreu, 1994; De Dreu et al., 1994). There seems to be a general tendency of inequality aversion for positively framed problems and a tendency towards inequality seeking for negative framed problems. Loss framed individuals are more concerned with maximizing their own payoff and gain framed individuals are more concerned with reaching a fair distribution of outcomes. De Dreu et al. (1994) point the role of loss aversion in explaining these results. However recent papers by Buchan et al. (2005); Leliveld et al. (2009) and Zhou and Wu (2011) find evidence that fairness seem to play a different role when individuals face losses than when they face

\footnotetext{
${ }^{1}$ see e.g. evidence by Kahneman and Thaler (1991) for the endowment effect, Samuelson and Zeckhauser (1988) for the sunk-cost fallacy, Benartzi and Thaler (1995) for the equity premium puzzle, Rabin (2000) for risk aversion and small stakes or Abeler et al. (2011) for the effect of labor target earnings.
} 
gains. Using ultimatum games these studies reveal that the size of the offers is related to strategic concerns in the gain domain, while it is related to other-regarding concerns in the loss domain.

The previous results have been obtained using ultimatum games. However, as argued by Blanco et al. (2011), the behavior of players in ultimatum games and in dictator games is likely to be different due to the notion of responsibility and strategic situations. The dictator game purely measures individuals' inequality aversion in a non-strategic situation, whereas in ultimatum games players are in a strategic situation and are not purely concerned by equalizing outcomes, but rather driven by the expectations of reciprocity.

In this paper we study other-regarding preferences both when the decision making is framed with gains and losses. Relying on Fehr and Schmidt (1999) model of inequality aversion, we compare advantageous inequality aversion in the gain and in the loss frame. Individuals experiencing advantageous inequality aversion are willing to give up something good, because it is more than someone else is getting. We follow Blanco et al. (2011) and use their modified dictator game (MDG hereafter) that we frame it either with gains or losses although keeping outcome payoff equivalent. This allows us to elicit a parameter of aversion to advantageous inequality called the "guilt parameter" both for gains and losses.

We make theoretical predictions on the basis of the model by Fehr and Schmidt (1999) in which we introduce a parameter of loss aversion when the dictator has to decide on how to allocate losses. The predictions are such that individuals should be more reluctant to sacrifice money in order to equalize outcomes between partners when they face losses than when they face gains. Our experimental results show that loss framed individuals are less inequality averse compared to gain framed individuals. This means that loss framed individuals maximize their own outcomes while gain framed individuals are more concerned in achieving a more equal distribution of outcomes. Furthermore, the results suggest also that women are more inequality averse than men.

This paper is organized as follows. Section2 outlines the experimental design and Section 3 discusses the theoretical predictions. In Section 4 we present the results of the experiment. Finally, we conclude in section 5. 


\section{Experimental Design}

We use data from two different experiments that were initially dedicated to another question than the one at the core of this paper (see Attanasi et al. (2016) and Lampach et al. (2016)). From these two experiments, we retrieve data from a MDG similar to Blanco et al. (2011). Indeed while in both experiments the subjects had to perform several other tasks, they first start by playing a MDG presented below. The two experiments diverge according to the frame: either gains or losses. In Attanasi et al. (2016), subjects are facing outcomes in the gain domain, we call it $T_{G}$ hereafter. In Lampach et al. (2016), subjects are confronted with outcomes in the loss domain, $T_{L}$ hereafter.

\subsection{The modified dictator game}

The aim of the MDG introduced by Blanco et al. (2011) is to elicit the point prediction of the guilt parameter measuring aversion to advantageous inequality as in Fehr and Schmidt (1999).

In the gain frame treatment, the dictator has to decide about how much of the initial amount of $€ 10$ she is willing to sacrifice to the recipient in order to attain an equal distribution of outcomes. More specifically, in our experiment, subjects are presented with a list of 11 pairs of payoff vectors that contain the dictator and the recipient's payoff. In all 11 cases, subjects have to choose sequentially one of the two payoff vectors. The left payoff vector is always $(€ 10, € 0)$, that is, if this vector was chosen, the dictator would receive $€ 10$ and the recipient nothing. The right payoff contains equal outcomes varying from $(€ 0, € 0),(€ 1, € 1)$ all the way to $(€ 10, € 10)$.

In the loss frame treatment, the type of decision is similar to the gain frame except that subjects decide about potential losses. To compensate for eventual losses; subjects receive an endowment of $€ 10$. The left payoff vector is always $(€ 0 ; €-10)$ and the right payoff vector contains equal payoffs varying from $(€-10, €-10),(€-9, €-9)$ throughout to $(€ 0, € 0)$.

Table 1 illustrates the differences of the payoff vectors between the gain and loss frame treatments. More precisely, the task of $T_{G}$ compared to $T_{L}$ differs by the sign of the payoff 
vectors for option "Left" and option "Right". Hence, the payoff vectors in both treatments can be considered as identical and solely differ by the frame changing. In both treatments, we have fixed the first and last decision line to suppress inconsistent choices.

Table 1: Modified dictator game in the gain and loss frame

\begin{tabular}{lccccc}
\hline \hline & \multicolumn{2}{c}{ Gain frame $\left(T_{G}\right)$} & & \multicolumn{2}{c}{ Loss frame $^{*}\left(T_{L}\right)$} \\
\cline { 2 - 3 } \cline { 5 - 6 } Decision & Option Left & Option Right & & Option Left & Option Right \\
\hline 1 & $(€ 10, € 0)$ & $(€ 0, € 0)$ & & $(€ 0, €-10)$ & $(€-10, €-10)$ \\
2 & $(€ 10, € 0)$ & $(€ 1, € 1)$ & & $(€ 0, €-10)$ & $(€-9, €-9)$ \\
3 & $(€ 10, € 0)$ & $(€ 2, € 2)$ & & $(€ 0, €-10)$ & $(€-8, €-8)$ \\
4 & $(€ 10, € 0)$ & $(€ 3, € 3)$ & & $(€ 0, €-10)$ & $(€-7, €-7)$ \\
5 & $(€ 10, € 0)$ & $(€ 4, € 4)$ & & $(€ 0, €-10)$ & $(€-6, €-6)$ \\
6 & $(€ 10, € 0)$ & $(€ 5, € 5)$ & & $(€ 0, €-10)$ & $(€-5, €-5)$ \\
7 & $(€ 10, € 0)$ & $(€ 6, € 6)$ & & $(€ 0, €-10)$ & $(€-4, €-4)$ \\
8 & $(€ 10, € 0)$ & $(€ 7, € 7)$ & & $(€ 0, €-10)$ & $(€-3, €-3)$ \\
9 & $(€ 10, € 0)$ & $(€ 8, € 8)$ & & $(€ 0, €-10)$ & $(€-2, €-2)$ \\
10 & $(€ 10, € 0)$ & $(€ 9, € 9)$ & $(€ 0, €-10)$ & $(€-1, €-1)$ \\
11 & $(€ 10, € 0)$ & $(€ 10, € 10)$ & $(€ 0, €-10)$ & $(€ 0, € 0)$ \\
\hline \hline
\end{tabular}

Note: * Subjects receive an endowment of $€ 10$ to compensate potential negative payoffs. In both cases, if player A prefers "Left" for a certain line (amount $€ X$ ), the computer automatically proposes the same choice for the lines lower than X. Similarly, if player A prefers "Right" for a certain line (€X), the computer proposes player $A$ automatically the same alternative for the adjacent lines higher than $X$. We require subjects to choose "Left" for the amount $X$ equal to $€-10$ (€0) and "Right" for the amount $X$ equal to $€ 0(€ 10)$.

One needs to bear in mind that any difference between the two treatments could be attributed to the effect of the frame changing for one owns payoffs, the frame changing for the other player's payoffs or a combination of both. Ideally, switching treatments to the loss frame while the dictator changes to the loss frame and the recipient stays in the gain frame or the dictator remains in the gain frame while the recipient changes to the loss frame would tease out which of the two variations is causing the results. The comparison 
of our two treatments does not allow to disentangle the effect of loss aversion from frame changing.

\subsection{Procedures}

Table 2 presents summary design information ${ }^{2}$. We consider a between-subject design and implement two distinct treatments which differ according to the framing: either gain or loss. As presented above, we used data from two samples of experiments that were run in the Economic Experimental Laboratory at the University of Strasbourg (France). In both experiments, subjects start by playing a MDG but after this first task, several other tasks follow which were not known by the subjects at the time of playing the MDG. In Attanasi et al. (2016), there were in total three tasks: ( $i$ ) elicitation of advantageous inequality aversion, (ii) risk aversion, and (iii) a strategic game. Lampach et al. (2016) introduced four tasks in the experiment: $(i)$ elicitation of advantageous inequality aversion, (ii) risk aversion, (iii) ambiguity aversion and (iv) a liability game. Subjects did not receive any feedback or payment until the end of the experiment. All decisions were to be made as the role of dictator, without any information on other subjects' choices, and without any communication. At the end of the session, each task counted for the calculation of the gains and subjects were paid according to their decisions in the tasks.

Table 2: Treatment conditions

\begin{tabular}{lccccc}
\hline \hline & & & & & \\
Experiment & Treatment & Number of subjects & Session date & Sessions & Number of tasks \\
\hline & & & & & \\
Attanasi et al. (2016) & Gain frame $\left(T_{G}\right)$ & 160 & July to October 2013 & 8 & 3 \\
Lampach et al. (2016) & Loss frame $\left(T_{L}\right)$ & 160 & November 2015 & 8 & 4 \\
\hline \hline
\end{tabular}

At the end of the experiment, in the MDG, one of the 11 payoff vector pairs is randomly chosen to determine the payment. Each subject is also randomly assigned the role of the dictator or the recipient. This role uncertainty could affect subjects' behavior. Iriberri and Rey-Biel (2011) have shown that this may explain different behavior in decisions with interdependent preferences. This is a rather unexplored question in the literature

\footnotetext{
${ }^{2}$ Instructions are presented in Supplementary Materials.
} 
(Charness and Grosskopf, 2001). In our case this might not be a problem since role uncertainty is present in our two treatments.

We run eight sessions per treatment with 20 subjects each. Subjects were recruited with ORSEE (Greiner, 2015) and we made sure that subjects did not participate in both studies. The two experiments were conducted at two different instances in time: $T_{G}$ in Summer and Fall 2013 and $T_{L}$ in Fall 2015. In total, we gather 160 independent observations per treatment.

\section{Theoretical predictions}

Let us assume that the dictator behaves according to a piecewise linear preferences function exhibiting inequality aversion à la Fehr and Schmidt (1999):

$$
U_{i}(x)=x_{i}-\alpha_{i} \max \left\{x_{j}-x_{i}, 0\right\}-\beta_{i} \max \left\{x_{i}-x_{j}, 0\right\}, \quad i \neq j
$$

where $U_{i}$ denotes the utility function of player $i, x_{i, j}$ represents the monetary payoffs to player $\mathrm{i}$ or $\mathrm{j}, \alpha_{i}$ is the parameter of envy measuring the marginal disutility of disadvantageous inequality and $\beta_{i}$ is the guilt parameter ${ }^{3}$ measuring the marginal disutility of advantageous inequality. Fehr and Schmidt (1999) make two assumptions: $\alpha_{i} \geq \beta_{i}$ and $0 \leq \beta_{i} \leq 1$. The first assumption captures the idea that individuals in a disadvantageous position suffer at least as much disutility as those in a advantageous position. The second assumption excludes individuals who like to be better off than others $\left(0 \leq \beta_{i}\right)$ and rules out individuals who are willing to throw money away to reduce inequality $\left(\beta_{i} \leq 1\right)$.

In our experiment, we seek to elicit the guilt parameter $\beta$ when individuals face either negative or positive outcomes. We derive the distribution of $\beta$ from the MDG responder decisions. We measure exact values for $\beta_{i}$ such that the dictator is indifferent between two allocations, the egalitarian $\left(x_{i}, x_{i}\right)$ and unfair allocation $\left(x_{i}, x_{j}\right)$ where $x_{i}>x_{j}$. We provide a point estimate for $\beta$ where an individual switches to the egalitarian outcome at $\left(x_{i}^{\prime}, x_{i}^{\prime}\right)$. If an individual switches at the point $\left(x_{i}^{\prime}, x_{i}^{\prime}\right)$, it means that the person prefers the egalitarian $\left(x_{i}^{\prime}, x_{i}^{\prime}\right)$ over the unfair distribution $\left(x_{i}, x_{j}\right)$. For instance, an individual

\footnotetext{
${ }^{3}$ Blanco et al. (2011) refers to it as guilt parameter.
} 
switches to the egalitarian outcome at $\left(x_{i}^{\prime}, x_{i}^{\prime}\right)$. This means that the individual prefers the unfair allocation $\left(x_{i}, x_{j}\right)$ over the egalitarian outcome $\left(x_{i}^{\prime}-1, x_{i}^{\prime}-1\right)$ but $\left(x_{i}^{\prime}, x_{i}^{\prime}\right)$ over $\left(x_{i}, x_{j}\right)$.

Similarly to Blanco et al. (2011), in the gain framed treatment, we solve for the guilt parameter $\beta_{i}^{G}$ when the individual is indifferent between the unfair $\left(x_{i}, x_{j}\right)$ and egalitarian distribution $\left(\tilde{x_{G}}, \tilde{x_{G}}\right)$ where $\tilde{x_{G}} \in\left[x_{i}^{\prime}-1, x_{i}^{\prime}\right]$ and $x_{i}^{\prime} \in\{1, \ldots, 10\}$. The superscript "G" denotes the gain framed treatment. From equation (1), we get $U_{i}\left(x_{i}, x_{j}\right)=\tilde{U_{i}}\left(\tilde{x_{G}}, \tilde{x_{G}}\right)$ if and only if $x_{i}-\beta_{i}^{G}\left(x_{i}-x_{j}\right)=\tilde{x_{G}}$ which yields the critical $\beta_{i}^{G}$ :

$$
\beta_{i}^{G}=\frac{x_{i}-\tilde{x_{G}}}{\left(x_{i}-x_{j}\right)}
$$

With $x_{i}=10$ and $x_{j}=0$ then equation (2) can be re-written:

$$
\beta_{i}^{G}=1-\frac{\tilde{x_{G}}}{10}
$$

In the loss framed treatment, if we assume that individuals process losses differently from gains due to the perception of a reference point (Kahneman and Tversky, 1979; Kahneman and Thaler, 1991; Kőszegi and Rabin, 2006; Köbberling and Wakker, 2005), thus the value of $\beta$ may be different than what we obtain in the gain domain. More particularly, if individuals experience loss aversion such that they try to avoid a loss more than they will do to pursue a gain, according to Tversky and Kahneman (1992), the utility can be represented as a composition of a loss aversion index $\lambda$ and the basic utility function $U$ such that the utility of a loss $x$ is given by $U(-x)=-\lambda U(x)$. Loss aversion implies that $\lambda$ is bigger than one reflecting the fact that losses count for more than gains in terms of utility.

We solve for the guilt parameter $\beta_{i}^{L}$ while assuming loss aversion when the individual is indifferent between the unfair $\left(x_{i}, x_{j}\right)$ and egalitarian distribution $\left(\tilde{x_{L}}, \tilde{x_{L}}\right)$ where $\tilde{x_{L}} \in$ $\left[x_{i}^{\prime}-1, x_{i}^{\prime}\right]$ and $x_{i}^{\prime} \in\{-9, \ldots, 0\}$. Assuming piecewise linear utility function, we consider a model where the dictator values the negative outcomes $x$ at $\lambda x^{4}$. From equation (1), we get $U_{i}\left(x_{i}, x_{j}\right)=U_{i}\left(\tilde{x_{L}}, \tilde{x_{L}}\right)$ if and only if $\lambda\left(x_{i}-\beta_{i}^{L}\left(x_{i}-x_{j}\right)\right)=\tilde{x_{L}}$ which yields the

\footnotetext{
${ }^{4}$ Without loss of generality, $U(0)=0$.
} 
critical $\beta_{i}^{L}$ :

$$
\beta_{i}^{L}=\frac{x_{i}-\frac{\tilde{x_{L}}}{\lambda}}{\left(x_{i}-x_{j}\right)}
$$

where the superscript " $L$ " denotes the loss framed treatment. With $x_{i}=0$ and $x_{j}=-10$, it follows from equation (4):

$$
\beta_{i}^{L}=-\frac{\tilde{x_{L}}}{10 \lambda}
$$

Since $\tilde{x_{L}}$ is negative, $\beta_{i}^{L}$ is positive $\left(0<\beta_{i}^{L}<1\right)$. When $\lambda>1$, it means that losses are overvalued relative to gains. The comparison of (5) with (3) yields that the guilt parameter in the loss frame will be lower than in the gain frame for the same monetary

amount $\left|x_{i}^{\prime}\right|$. An individual might feel very guilty for leaving the other person with a high loss. If $\lambda=1$, gains and losses are valued equally, the guilt parameter will be the same in the loss as in the gain frame.

Hence, we expect the guilt parameter to be lower in the loss frame than in the gain frame. This is not because individuals perceive a different level of inequality aversion in both frames, but due to loss aversion inducing a greater sensitivity to losses than to gains. It thus implies a change on the amount individuals are willing to give up for another person. Individuals will be more reluctant in the loss than in the gain frame to sacrifice money in order to achieve an equal distribution of outcomes.

\section{Empirical results}

Figure 1 sketches the cumulative distribution function of the parameter of advantageous inequality aversion in each treatment. The comparison of the cumulative distribution function clearly demonstrates that loss framed individuals have lower fairness preferences than gain framed. The average value of $\beta$ in $T_{G}$ is 0.523 with a standard deviation of 0.216 and the average value in $T_{L}$ is 0.384 with a standard deviation of 0.251 . Both a parametric two-sided t-test $(p-$ value $<0.001)$ and a non-parametric two-sided Mann-Whitney test $(p-$ value $<0.001)$ indicate that the average inequality aversion parameter of gain compared to loss framed individuals is significantly different. This confirms that on average individuals are less likely to sacrifice money for an interdependent 
other person in the loss as in the gain frame $\left(\bar{\beta}^{L}<\bar{\beta}^{G}\right)$.

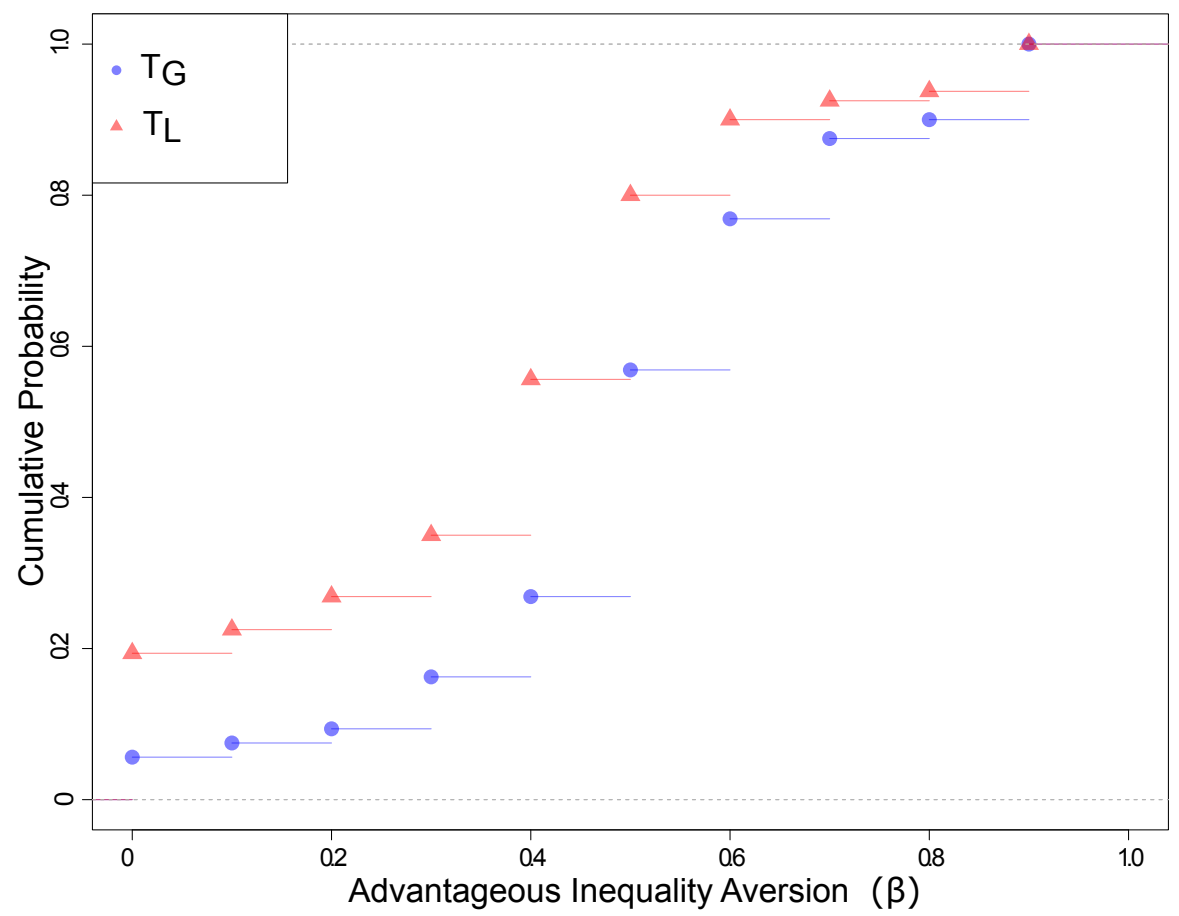

Figure 1: Cumulative Probability of Advantageous Inequality Aversion $\left(\beta^{G}, \beta^{L}\right)$ in the gain and the loss frame

In Table 3, we compare the distributions of guilt parameter as derived in our results and for the sake of comparison in Fehr and Schmidt (1999) and in Blanco et al. (2011). While our results are fairly comparable with Blanco et al. (2011), we shall stress that the results in Fehr and Schmidt (1999) are obtained with an ultimatum game. As we have already stressed above, the possibility of strategic behavior make the results hardly comparable.

Table 3: Distribution of $\beta$

\begin{tabular}{ccccc}
\hline \hline$\beta$ & Fehr and Schmidt (1999) & Blanco et al. (2011) & $T_{G}$ & $T_{L}$ \\
\hline$\beta<0.235$ & $30 \%$ & $29 \%$ & $10 \%$ & $27 \%$ \\
$0.235 \leq \beta<0.5$ & $30 \%$ & $15 \%$ & $17 \%$ & $28 \%$ \\
$0.5 \leq \beta$ & $40 \%$ & $56 \%$ & $73 \%$ & $45 \%$ \\
\hline
\end{tabular}


According to a Chi-square goodness of fit test, the distribution of the data in the gain frame differs significantly from both Fehr and Schmidt's (1999) intervals $\left(\chi^{2}=\right.$ 23.23, $\left.d f=2, p_{\text {value }}<0.001\right)$ and Blanco et al. $(2011)\left(\chi^{2}=11.62, d f=2, p_{\text {value }}=0.003\right)$. With regard to the loss frame, we find that there is no significant differences between our data and the intervals of Fehr and Schmidt $\left(\chi^{2}=11.62, d f=2, p_{\text {value }}=0.770\right)$ and a significant differences at the $10 \%$ level between our data and those of Blanco et al. (2011) $\left(\chi^{2}=11.62, d f=2, p_{\text {value }}=0.074\right)$. Overall, we observe that a large proportion of gain framed individuals at the extreme ends of the distribution choose an equal split and very few suggest an unfair offer. A possible explanation of these divergent results between Blanco et al. (2011) and ours can be found in the differences in sample size, the experimental design or the number of pay-off vectors ${ }^{5}$. Blanco et al. (2011) employ a within subjects design with a total of 62 subjects and include a list of 21 payoff vectors in MDG.

Unexpectedly the $\beta$ distribution in the loss frame is consistent with the one chosen in Fehr and Schmidt. Nevertheless, as pointed by Blanco et al. (2011) the distinction between strategic and non-strategic situation makes it difficult to directly compare our data distribution with the intervals of guilt parameter as derived by Fehr and Schmidt (1999). Furthermore, our finding systematically differs from Buchan et al. (2005); Leliveld et al. (2009) and Zhou and Wu (2011) who found that subjects have a higher demand for fairness when they have to share losses with others. Similarly, their findings have been obtained by applying an ultimatum game to determine disadvantageous inequality aversion by measuring responders' rejection rate.

\footnotetext{
${ }^{5}$ Blanco et al. (2011) uses a much smaller sample size $(\mathrm{n}=62)$ compared to $T_{G}(\mathrm{n}=160)$. A recent paper by Button et al. (2013) stresses that low statistical power due to small sample size of studies negatively affects the likelihood that the statistically significant results reflect a true effect. Larger sample size reduces the likelihood of encountering the occurrence of Type-I and II errors if the experimental design is carefully constructed and no other problems occur. Furthermore, a higher sample size increases the confidence of the results. Since it is expected that the larger the sample size, the more accurately it reflects the behavior of the whole group.
} 


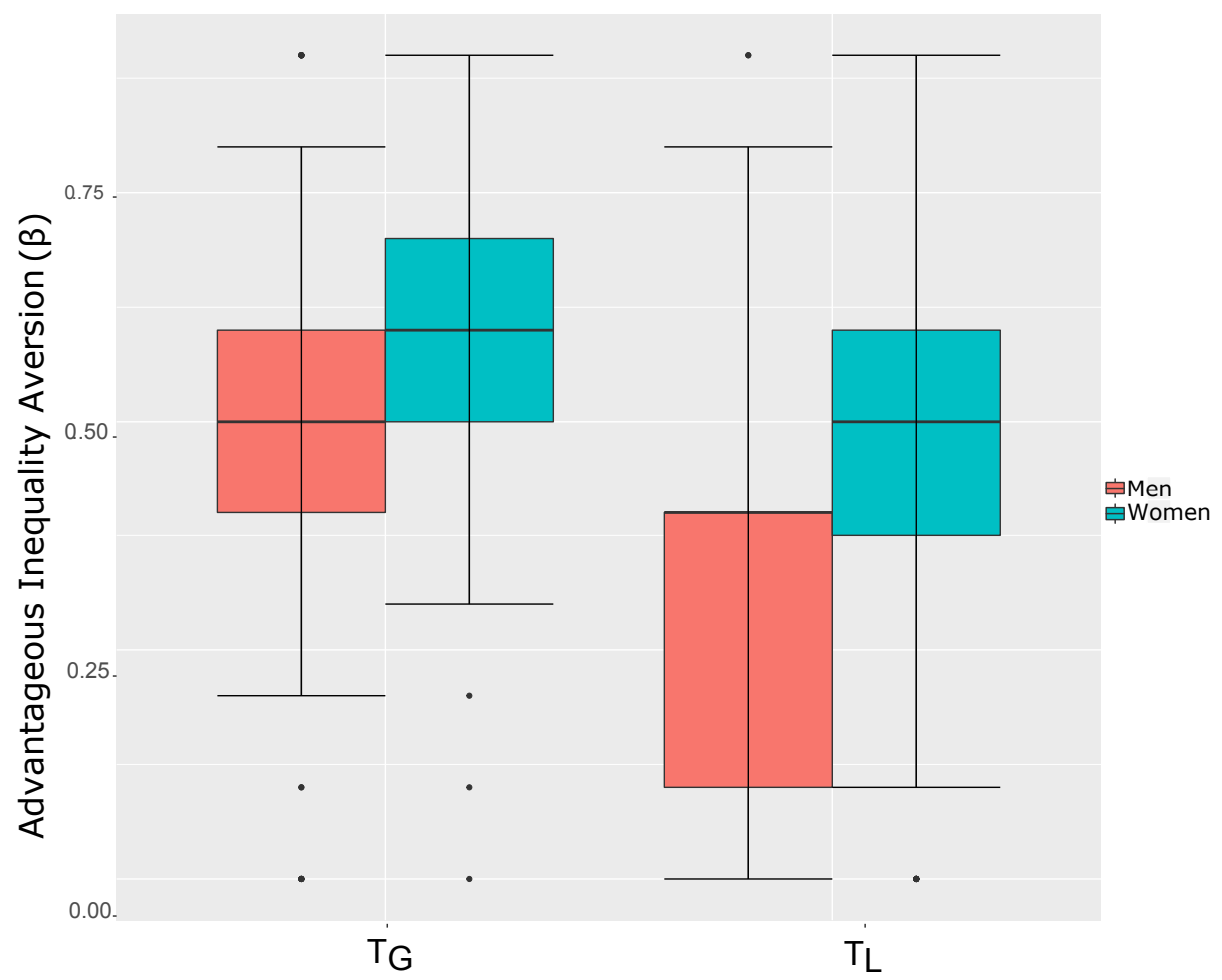

Figure 2: Gender Differences of Fairness Preferences

Reviewing the literature, Croson and Gneezy (2009) have emphasized that women are in general more inequality averse than men (see i.e. (Selten and Ockenfels, 1998; Andreoni and Vesterlund, 2001; Dickinson and Tiefenthaler, 2002; Dufwenberg and Astri, 2005; Croson and Gneezy, 2009)). In Figure 2, we compare the distribution of the guilt parameter $\left(\beta_{i}\right)$ between men and women in the gain and loss frame. The fairness preferences of women differ to a large extend from those of men. A two-sided Mann-Whitney test indicates significant differences between women and men in the gain frame $\left(p_{\text {value }}=0.003\right)$ and in the loss frame treatment $\left(p_{\text {value }}<0.001\right)$. This result is in line with Andreoni and Vesterlund (2001) and Dickinson and Tiefenthaler (2002) who also find that women are more concerned about achieving equal outcomes between two parties.

Finally in Table 4 we implement a multiple regression analysis to explore the determinants influencing individual's fairness preferences. We report cluster robust standard errors to control for individual heterogeneity among both samples (Cameron and Miller, 2015). 
Table 4: Effects of gain-loss frames on advantageous inequality aversion

\begin{tabular}{|c|c|}
\hline Dependent variable: & $\beta$ \\
\hline \multirow[t]{2}{*}{ Constant } & $0.455^{* * *}$ \\
\hline & $(0.093)$ \\
\hline \multirow[t]{2}{*}{$T_{L}$} & $-0.151^{* * *}$ \\
\hline & $(0.027)$ \\
\hline \multirow[t]{2}{*}{ Female } & $0.114^{* * *}$ \\
\hline & $(0.026)$ \\
\hline \multirow[t]{2}{*}{ Age } & -0.001 \\
\hline & $(0.004)$ \\
\hline \multirow[t]{2}{*}{ Higher School } & 0.042 \\
\hline & $(0.030)$ \\
\hline \multirow[t]{2}{*}{ Bachelor } & 0.006 \\
\hline & $(0.048)$ \\
\hline \multirow[t]{2}{*}{ Master } & 0.026 \\
\hline & $(0.230)$ \\
\hline \multirow[t]{2}{*}{ Human and social sciences } & 0.033 \\
\hline & $(0.033)$ \\
\hline \multirow[t]{2}{*}{ Arts and Philosophy } & -0.008 \\
\hline & $(0.039)$ \\
\hline Observations & 320 \\
\hline $\mathrm{R}^{2}$ & 0.152 \\
\hline Adjusted $\mathrm{R}^{2}$ & 0.130 \\
\hline Residual Std. Error & $0.227(d f=311)$ \\
\hline F statistic & $6.970^{* * *}(d f=8 ; 311)$ \\
\hline
\end{tabular}

The dependent variable-measured as the individuals' fairness preference $\left(\beta_{i}\right)$-is expressed as a linear function of the treatment effect (gain-loss frame), gender and other socio-demographic variables, such as age, educational level and field of studies. The estimation results confirm our previous findings by showing that loss framed individuals are more reluctant to equalize the outcomes between partners. On average women are significantly more inequality averse compared to men. However, we do not find any significant effect for the covariates age, educational level and field of studies. 


\section{Conclusion}

Monetary losses are encountered in many economic situations as well as in social dilemmas. Understanding the nature of social preferences in the domain of losses is therefore highly relevant to uncover important characteristics of individual behavior. In this paper, we contribute to the literature on the determinants of other-regarding preferences by providing new evidence on inequality aversion when the decision is framed with losses. Our results suggest that individuals tend to dislike inequality more in the gain than in the loss frame. Differences in levels of inequality between both treatments can partly be explained by loss aversion. In this case, individuals value prospective losses with greater sensitivity relative to a reference point and this might drive them towards a more unfair behavior. In line with the literature, our findings reveal that women are more inequality averse than men.

These results may have substantial implications for decision making in which allocation and distribution rules matter. For instance, in the case of family law, equality should be less important to individuals in the situation of splitting liabilities than dividing assets. Also when negotiated over losses rather gains, bargaining outcomes are likely to be different. This has important implications in real-life situations as gain-loss frames can induce different responses in bargaining behavior and negotiated outcomes (Schweitzer and DeChruch, 2001; Carnevale, 2008).

However our design has some limitations. We have not elicited the degree of loss aversion, nor can we distinguish whether it is the change in the framing or the loss aversion that affect individuals' level of inequality aversion. To gain a better understanding on how frames influence individuals' social preferences, it might be desirable to conduct multiple experiments with different individuals from diverse backgrounds and demographics.

Furthermore, the replication of previous experiments might contribute to understanding the robustness and generalizability of individuals' behavior (Deck et al., 2015; Camerer et al., 2016). Future research could fill this void and a variety of additional games would be useful for studying social preferences. 


\section{References}

Abeler, J., A. Falk, L. Goette, and D. Huffman (2011). Reference points and effort provision. The American Economic Review 101(2), 470-492.

Andreoni, J. and L. Vesterlund (2001). Which Is the Fair Sex? Gender Differences in Altruism. Quarterly Journal of Economics 116, 293-312.

Attanasi, G., K. Boun My, N. Georgantzis, and M. Ginés (2016). Strategic altruism as complementarity-building investment. mimeo.

Benartzi, S. and R. Thaler (1995). Myopic Loss Aversion and the Equity Premium Puzzle. The Quarterly Journal of Economics 110(1), 73-92.

Blanco, M., D. Engelmann, and H. T. Normann (2011). A within-subject analysis of other-regarding preferences. Games and Economic Behavior 72(2), 321 - 338.

Bolton, G. E. and A. Ockenfels (2000). Erc: A theory of equity, reciprocity, and competition. The American Economic Review 90(1), 166-193.

Buchan, N., R. Croson, E. Johnson, and G. Wu (2005). Gain and Loss Ultimatums, Volume 13, Chapter 3, pp. 1-23. Advances in Applied Microeconomics. Greenwich, CT: JAI Press.

Button, K., J. Ioannidis, C. Mokrysz, B. Nosek, J. Flint, E. Robinson, and M. Munafò (2013). Power failure: why small sample size undermines the reliability of neuroscience. Nature Reviews Neuroscience 365, 365-376.

Camerer, C. F., A. Dreber, E. Forsell, T.-H. Ho, J. Huber, M. Johannesson, M. Kirchler, J. Almenb, A. Altmejd, T. Chan, E. Heikensten, F. Holzmeister, T. Imai, S. Isaksson, G. Nave, T. Pfeiffer, M. Razen, and H. Wu (2016). Evaluating replicability of laboratory experiments in economics. Science, 1-9.

Cameron, C. and D. Miller (2015). A practitioner's guide to cluster-robust inference. Journal of Human Resources 50(2). 
Carnevale, P. (2008). Positive affect and decision frame in negotiation. Group Decision Negotiation 17(1), 51-63.

Charness, G. and B. Grosskopf (2001). Relative payofss and hapiness: an experiment study. Journal of Economic Behavior and Organization 45, 301-328.

Charness, G. and M. Rabin (2002). Understanding social preferences with simple tests. Quarterly Journal of Economics 117(3), 817 - 869.

Croson, R. and U. Gneezy (2009). Gender differences in preferences. Journal of Economic Literature $47(2), 448-74$.

De Dreu, C. (1994). Effects of gain-loss frames on satisfaction with self-other outcome differences. European Journal of Social Psychology 24, 497-510.

De Dreu, C., P. Carnevale, B. Emans, and E. Van De Vliert (1994). Effects of gain-loss frames in negotiation: Loss aversion, mismatching, and frame adoption. Organizational Behavior and Human Decision Processes 60, 90-107.

Deck, C., E. Fatas, and T. Rosenblat (Eds.) (2015). Replication in Experimental Economics. Emerald.

Dickinson, D. L. and J. Tiefenthaler (2002). What Is Fair? Experimental Evidence. Southern Economic Journal 69(2), 414-428.

Dufwenberg, M. and M. Astri (2005). Gender composition in teams. Journal of Economic Behavior \& Organization 61, 50-54.

Fehr, E. and U. Fischbacher (2006). The economics of fairness, reciprocity and altruism - experimental evidence and new theories. Hnadbook of the Economics of Giving, Altruism and Reciprocity 1, 615-691.

Fehr, S. and K. Schmidt (1999). A theory orf fairness competition and cooperation. The Quarterly Journal of Economics 114(3), 817-868.

Greiner, B. (2015). Subject pool recruitment procedures: organizing experiments with ORSEE. Journal of the Economic Science Association 1(1), 114-125. 
Iriberri, N. and P. Rey-Biel (2011). The role of role uncertainty in modified dictator games. Experimental Economics 14(2), 160-180.

Kahneman, D. (1992). Decision processes in negotiation reference points, anchors, norms, and mixed feelings. Organizational Behavior and Human Decision Processes 51 (2), 296 $-312$.

Kahneman, D. and A. Tversky (1979). Prospect theory: An analysis of decision under risk. Econometrica: Journal of the econometric society, 263-291.

Kahneman, D., K. J. and R. Thaler (1991). Anomalies: The endowment effect, loss aversion, and status quo bias. Journal of Economic Perspectives 5(1), 193-206.

Köbberling, V. and P. P. Wakker (2005). An index of loss aversion. Journal of Economic Theory 122(1), 119-131.

Kôszegi, B. and M. Rabin (2006). A model of reference-dependent preferences. The Quarterly Journal of Economics 121(4), 1133-1165.

Lampach, N., K. Boun My, and S. Spaeter (2016). Risk, ambiguity and efficient liability rules: An experiment. BETA Working Paper 2016-30.

Leliveld, M., I. van Beest, and a. A. van Dijk, E. (2009). Understanding the influence of outcome valence in bargaining: A study on fairness accessibility, norms, and behavior. Journal of Experimental Social Psychology 45(1), 505-514.

Loewenstein, G., L. Thompson, and M. Bazerman (1989). Social utility and decision making in interpersonal contexts. Journal of Personality and Social Psychology 57(3), $426-441$.

Poppe, M. and H. Valkenberg (1993). Effects of gain versus loss and certain versus probable outcomes on social value orientations. European Review of Social Psychology 33(3), $331-337$.

Rabin, M. (2000, September). Risk Aversion and Expected-Utility Theory: A Calibration Theorem. Econometrica 68(5), 1281-1292. 
Samuelson, W. and R. Zeckhauser (1988, March). Status Quo Bias in Decision Making. Journal of Risk and Uncertainty 1(1), 7-59.

Schweitzer, E. and L. DeChruch (2001). Linking frames in nnegotiations: Gains, losses and conflict frame adoption. The International Journal of Conflict Management 12(2), $100-113$.

Selten, R. and A. Ockenfels (1998). An experimental solidarity game. Journal of Economic Behavior 8 Organization $34(4), 517-539$.

Zhou, X. and Y. Wu (2011). Sharing losses and sharing gains: Increased demand for fairness under adversity. Journal of Experimental Social Psychology 47(3), 582 - 588. 